\section{Benchtop and Microcen- trifuge Preparation of Pseudomonas aeruginosa Competent Cells}

\section{BioTechniques 33:760-763 (October 2002)}

Although indispensable for the introduction of DNA fragments manipulated in vitro into bacteria, transformation using chemically prepared competent or electrocompetent cells is still a rather slow and labor-intensive technique, and apart from waiting for transformants to appear on selective plates, the preparation of competent cells is the slowest part of the whole process. Most published transformation protocols for use with Pseudomonas aeruginosa are modifications of protocols developed for $E$. coli and either involve electrocompetent cells $(1-4,9,12)$ or cells made competent by chemical treatment $(8,10)$. Conventional chemical transformation of $P$. aeruginosa has many drawbacks, most notably low transformation efficiencies and/or time-consuming procedures. Therefore, electroporation has become the method of choice for this bacterium.
However, the preparation of low-ionic strength DNA and competent cells for electroporation is still a critical and relatively time-consuming process. Here we describe the adaptation of a rapid benchtop- and microcentrifuge-based method previously reported (14) for obtaining low-efficiency competent $E$. coli cells to prepare highly competent $P$. aeruginosa cells for chemical transformation. For P. aeruginosa, this method yields transformation efficiencies that are comparable to those observed when using electroporation.

For preparation of competent $P$. aeruginosa cells, strain PAO1 cells were grown in $4 \mathrm{~mL} \mathrm{LB}$ broth (Difco Laboratories, Detroit, MI, USA) at $37^{\circ} \mathrm{C}$ until they reached saturation (usually overnight). All of the following steps, except the centrifugations, were performed with the tubes sitting on ice. A 1.5-mL microcentrifuge tube was pre-chilled on ice for 3-5 min. Aliquots $(1 \mathrm{~mL})$ of a stationary phase or overnight $P$. aeruginosa culture were transferred to the chilled microcentrifuge tubes, and the cells were harvested at room temperature by a short centrifugation for $30 \mathrm{~s}$ at approximately $13000 \times g$. Centrifugations longer than $30 \mathrm{~s}$ are not recommended because they cause significant reduction of transformation efficiencies. The cell pellets were resuspended with a pipet tip in $1 \mathrm{~mL}$ cold (approximately $4^{\circ} \mathrm{C}$ ) $0.1 \mathrm{M} \mathrm{MgCl}_{2}$. The cell suspension was again centrifuged at approximately $13000 \times g$ for $30 \mathrm{~s}$ at room temperature. The supernatant was removed, and the cell pellets were resuspended with a pipet tip in $1 \mathrm{~mL}$ cold transformation salts with glycerol (TG salts) solution (75 $\mathrm{mM} \mathrm{CaCl} 2,6 \mathrm{mM} \mathrm{MgCl}_{2}, 15 \%$ glycerol). The cell suspensions were kept on ice for $10 \mathrm{~min}$ and then centrifuged at approximately $13000 \times g$ for $30 \mathrm{~s}$ at room temperature. After decanting the supernatant, the pellets were then resuspended with a pipet tip in 200 $\mu \mathrm{L}$ cold TG salt solution and kept on ice until use. At this stage, the cells were ready for transformation.

The transformation efficiency of $P$. aeruginosa cells prepared using this procedure was determined using the 4.2-kb broad-host-range plasmid pUCP20T (11). Aliquots $(100 \mu \mathrm{L})$ of the competent cells were transferred to thin-walled $13 \times 100 \mathrm{~mm}$ borosilicate glass tubes (VWR Scientific, South Plainfield, NJ, USA) that were prechilled on ice. Next, 2-5 $\mu \mathrm{L}$ aliquots containing 100-1000 ng pUCP20T DNA that has been purified using the Qiagen ${ }^{\circledR}$ Midiprep kit (Qiagen, Valencia, CA, USA) and suspended in either $10 \mathrm{mM}$ Tris- $\mathrm{HCl}(\mathrm{pH} 8.5)$ or sterile water were added to the cells (DNA in this buffer or water yielded the same transformation efficiencies). A negative control received sterile water instead of plasmid DNA. This DNA-cell mixture was incubated on ice for $15 \mathrm{~min}$. The mixture was then heat-shocked at $37^{\circ} \mathrm{C}$ for $2 \mathrm{~min}$, and $500 \mu \mathrm{L} \mathrm{LB}$ broth were immediately added. The tubes were incubated at $37^{\circ} \mathrm{C}$ for $1 \mathrm{~h}$ in a shaking incubator. After incubation, a $200-\mu \mathrm{L}$ aliquot of each cell suspension was plated on LB agar containing 200 $\mu \mathrm{g} / \mathrm{mL}$ carbenicillin (Gemini Bio-Products, Woodland, CA, USA). The remaining contents of each tube were transferred to microcentrifuge tubes, and cells were harvested by centrifugation at approximately $13000 \times g$ for 1 min at room temperature, resuspended in $200 \mu \mathrm{L}$ LB medium, and then spread on a LB-carbenicillin plate. The plates were incubated at $37^{\circ} \mathrm{C}$ for $20-24 \mathrm{~h}$ before colonies were counted.

Using the procedures described above for the preparation and transformation of competent $P$. aeruginosa PAO1 cells (Figure 1), we obtained $1 \times$ $10^{5}$ transformants/ $\mu \mathrm{g}$ pUCP20T DNA (Table 1), using an optimal DNA concentration of 200-400 ng. This transformation efficiency is comparable to the $1.1-1.5 \times 10^{5}$ transformants $/ \mu \mathrm{g}$ DNA when using most electroporation protocols $(1-4,9,12)$. Only two other reports indicated higher transformation efficiencies [i.e., $1.2 \times 10^{6}$ transformants/ $\mu \mathrm{g}$ DNA by using chemically prepared competent cells and a heat shock at $50^{\circ} \mathrm{C}(8)$ and approximately 2 $\times 10^{6}$ transformants/ $\mu \mathrm{g}$ DNA by employing an electroporation procedure (3)]. Although the transformation efficiency of competent cells prepared using our procedure is about 10-fold lower when compared to the most efficient procedures, it is comparable to those achieved with most published methods and therefore more than adequate for most laboratory applications. However, 
from $E$. coli must encounter significant restriction barriers when entering $P$. aeruginosa, the transformation efficiencies observed in E. coli were only 10 times higher than those observed with $P$. aeruginos $a$.

We have successfully used this procedure to transform many different $P$. aeruginosa mutant strains with vectors based on different replicons and also to simultaneously introduce two compatible plasmids into the same strain. However, we have not yet been able to obtain integrase-mediated insertion of integration-proficient vectors at the chromosomal $a t t B$ site (7), either by transfer of the suicide integration vector using this new method or by electroporation, but only by its conjugal transfer from $E$. coli. For routine transformations, two-day-old $P$. aeruginosa cultures have been used to prepare competent cells with lower but acceptable transformation efficiencies. Furthermore, competent cells in TG salts can be frozen at $-70^{\circ} \mathrm{C}$ for future use, although the transformation efficiency may decline slightly over time. In summary, because of its speed and efficiency, the procedure described here is an attractive alternative to the many other, more time-consuming methods available for the transformation of $P$. aeruginosa. With proper modification, it may be adaptable to other bacteria, as has already been demonstrated for $E$. coli.

\section{REFERENCES}

1.Dennis, J.J. and P.A. Sokol. 1995. Electrotransformation of Pseudomonas. In J.A. Nickoloff (Ed.), Methods in Molecular Biology: Electroporation Protocols for Microorganisms. Humana Press, Totowa, NJ.

2.Diver, J.M., L.E. Bryan, and P.A. Sokol. 1990. Transformation of Pseudomonas aeruginosa by electroporation. Anal. Biochem. 189:75-79.

3.Enderle, P.J. and M.A. Farwell. 1998. Electroporation of freshly plated Escherichia coli and Pseudomonas aeruginosa cells. BioTechniques 25:954-958.

4.Farinha, M.A. and A.M. Kropinski. 1990. High efficiency electroporation of Pseudomonas aeruginosa using frozen cell suspensions. FEMS Microbiol. Lett. 58:221-225.

5.Hengen, P.N. 1995. Electro-transformation of Escherichia coli with plasmid DNA. TIBS 20:248-249.

6.Hoang, T.T., R.R. Karkhoff-Schweizer, A.J. Kutchma, and H.P. Schweizer. 1998. A broad-host-range yeast Flp-FRT recombination system for site-specific excision of chro- mosomal DNA sequences: application for isolation of unmarked mutants of Pseudomonas aeruginosa. Gene 212:77-86.

7.Hoang, T.T., A.J. Kutchma, A. Becher, and H.P. Schweizer. 2000. Integration-proficient vectors for Pseudomonas aeruginosa: sitespecific integration and use for engineering of reporter and expression strains. Plasmid 43:59-72.

8.Irani, V.I. and J.J. Rowe. 1997. Enhancement of transformation in Pseudomonas aeruginosa PAO1 by $\mathrm{Mg}^{2+}$ and heat. BioTechniques 22:54-55.

9.Itoh, N., T. Kouzai, and Y. Koide. 1994. Efficient transformation of Pseudomonas strains with pNI vectors by electroporation. Biosci. Biotech. Biochem. 58:1306-1308.

10.Olsen, R.H., G. DeBusscher, and W.R. McCombie. 1982. Development of broad-hostrange vectors and gene banks: self-cloning of the Pseudomonas aeruginosa PAO chromosome. J. Bacteriol. 150:60-69.

11.Schweizer, H.P., T.R. Klassen, and T. Hoang. 1996. Improved methods for gene analysis and expression in Pseudomonas, p. 229-237. In T. Nakazawa, K. Furukawa, D. Haas, and S. Silver (Eds.), Molecular Biology of Pseudomonads. Am. Soc. Microbiol. Press, Washington, DC.

12.Smith, A.W. and B.H. Iglewski. 1989. Transformation of Pseudomonas aeruginosa by electroporation. Nucleic Acids Res. 17:10509.

13.Schweizer, H.P. 1998. Intrinsic resistance to inhibitors of fatty acid biosynthesis in Pseudomonas aeruginosa is due to efflux: application of a novel technique for generation of unmarked chromosomal mutations for the study of efflux systems. Antimicrob. Agents Chemother. 42:394-398.

14.Schweizer, H.P. and R.R. KarkhoffSchweizer. 1997. Design of bacterial hosts for lac-based expression vectors, p. 17-27. In R.S. Tuan (Ed.), Methods in Molecular Biology, Vol. 62, Recombinant Gene Expression Protocols. Humana Press, Totowa, NJ.

Work in the authors' laboratory is supported in part by a National Institutes of Health grant no. GM56685 to H.P.S. Address correspondence to Dr. Rungtip Chuanchuen, Department of Microbiology, Immunology and Pathology, Colorado State University, Fort Collins, CO 80523-1682A, USA.e-mail: rcc@lamar.colostate.edu

Received 26 April 2002; accepted 14 June 2002.

Rungtip Chuanchuen, Craig T. Narasaki, and Herbert P. Schweizer

Colorado State University

Fort Collins, CO, USA 